University of Nebraska - Lincoln

DigitalCommons@University of Nebraska - Lincoln

Faculty Publications: Department of Entomology

Entomology, Department of

January 2001

\title{
Development of European corn borer larvae on Event 176 Bt corn: Influence on survival and fitness
}

\author{
Blair D. Siegfried \\ University of Nebraska-Lincoln, bsiegfried1@ufl.edu \\ Amelia C. Zoerb \\ University of Nebraska-Lincoln \\ Terrence A. Spencer \\ University of Nebraska-Lincoln, tspencer1@unl.edu
}

Follow this and additional works at: https://digitalcommons.unl.edu/entomologyfacpub

Part of the Entomology Commons

Siegfried, Blair D.; Zoerb, Amelia C.; and Spencer, Terrence A., "Development of European corn borer larvae on Event 176 Bt corn: Influence on survival and fitness" (2001). Faculty Publications: Department of Entomology. 70.

https://digitalcommons.unl.edu/entomologyfacpub/70

This Article is brought to you for free and open access by the Entomology, Department of at DigitalCommons@University of Nebraska - Lincoln. It has been accepted for inclusion in Faculty Publications: Department of Entomology by an authorized administrator of DigitalCommons@University of Nebraska - Lincoln. 
Published in Entomologia Experimentalis et Applicata 100: 15-20, 2001.

Copyright (C 2001 Kluwer Academic Publishers. Used by permission. http://www.blackwell-synergy.com/loi/EEA

Accepted February 22, 2001.

\title{
Development of European corn borer larvae on Event 176 Bt corn: Influence on survival and fitness
}

\author{
Blair D. Siegfried, Amelia C. Zoerb \& Terence Spencer \\ Department of Entomology, 202 Plant Industry Bldg., University of Nebraska, Lincoln, NE 68583, USA \\ (Phone: +402 472-8714; Fax: +402 472-4687; E-mail: bsiegfried1@unl.edu)
}

\begin{abstract}
European corn borer larvae, Ostrinia nubilalis (Hübner) (Lepidoptera: Crambidae) that have completed development on Event 176 Bt corn hybrids have survived exposure to sublethal doses of the Cry1 Ab Bt toxin or are exploiting plant tissues that do not express the toxin. To evaluate the impact of such exposure, diapausing larvae were collected from Event 176 and conventional hybrids and compared for rates of pupation, parasitism, fitness (pupal weight, longevity, and fecundity) and susceptibility to the CrylAb toxin. Larvae completing development on Event 176 corn exhibited approximately 10\% higher survival rates and correspondingly lower parasitism rates than larvae completing development on conventional hybrids. No significant differences were detected in pupal weight, fecundity, longevity or susceptibility to the Cry1 Ab Bt toxin. These results indicate that survival on Event 176 corn are not adversely affect fitness and does not cause increased tolerance to the $\mathrm{Cry} 1 \mathrm{Ab}$ toxin in subsequent generations.
\end{abstract}

Key words: European corn borer, Bt corn, resistance management

\section{Introduction}

The predominant strategy proposed to manage resistance development in target pests of transgenic Bt crops involves the combination of a high dose of toxin expression in plant tissues and a refuge from exposure. This approach requires that the transgenic crop kill essentially all susceptible homozygotes and most heterozygous insects, leaving very few resistant homozygotes to survive (Ostlie et al., 1997; International Life Sciences Institute, 1998; Andow \& Hutchison, 1998). The refuge functions to provide a large pool of susceptible homozygotes to mate with rare resistant homozygotes such that their heterozygous progeny will be killed by the high dose of toxin expressed in the plants. High dose expression is believed to be necessary to insure that the inheritance of resistance is functionally recessive.

The integrity of the high-dose/refuge strategy may be compromised if a high dose of toxin is not achieved, and a high proportion of heterozygotes survive exposure (Gould, 1998). The high-dose expression of certain Bt transgenic maize hybrids has recently been questioned (International Life Sciences Institute, 1998; Andow \& Hutchison, 1998). Specifically, Event 176 hybrids express high levels of the Cry $1 \mathrm{Ab}$ toxin in green plant tissue and pollen, but extremely low levels in the silk and kernels (Koziel et al., 1993). Additionally, these hybrids are known to have reduced expression of the $\mathrm{Bt}$ toxin as the plant senesces (Ostlie et al., 1997). Because of the late season decline in Bt titer and relative absence in other tissues such as silk, kernels, and pith, significant survival of target pests such as European corn borer [Ostrinia nubilalis (Hübner)] larvae has been observed (B. Siegfried, unpubl.). As a consequence, exposure to these hybrids may result in increased fitness of heterozygotes and increased rates of resistance evolution. Therefore, Event 176 hybrids may not meet the high-dose criterion considered to be essential to effective resistance management.

Second generation European corn borer larvae completing development on Event $176 \mathrm{Bt}$ corn have potentially survived exposure to sublethal concentrations of the Cry1 Ab toxin. Sublethal exposure to Bt may increase sus- 
ceptibility to natural mortality factors or reduce rates of development. Slowed development has been observed when larvae are reared on artificial diet containing sublethal concentration of Bt toxin (B. Siegfried, unpubl.). Conversely, larvae developing on Event 176 hybrids may preferentially feed on tissues not expressing the Bt toxin, and are therefore able to complete development without exposure to the toxin. The objective of this study was to determine if survival on Event 176 corn hybrids affects $O$. nubilalis fitness or susceptibility of offspring to the Cry1 Ab toxin.

\section{Materials and methods}

Collections. In 1996 and 1997, commercial fields of Event 176 corn were identified by personnel from Mycogen Seeds and Novartis Seeds for field collection of $O$. nubilalis larvae. In 1996, 13 collections were obtained from Event 176 fields in areas of highest product sales from Nebraska, Iowa, and Illinois. In addition, 13 fields of comparable non-Bt hybrids (i.e., similar maturity date) were selected in the vicinity (within $10 \mathrm{~km}$ ) of the transgenic fields. In 1997, six fields of both Event 176 and non-Bt hybrids were identified from eastern Nebraska. Last instar, diapausing $O$. nubilalis larvae were collected by splitting stalks of unharvested corn or from stalk residue remaining after harvest. At least 50 larvae were collected from each field in 1996 and at least 200 were collected in 1997.

Rearing. Field collected larvae were immersed in $1 \%$ chlorine bleach to surface sterilize larvae and minimize mortality from disease. After surface sterilization, larvae were held individually in $0.5 \mathrm{ml}$ microfuge tubes with vented lids at $10{ }^{\circ} \mathrm{C}$ for at least 100 days in order to terminate diapause. Larvae were then moved individually to 16 well bioassay trays (CD International, Pitman, NJ) containing $1 \%$ agar as a source of moisture, and pupation occurred within the bioassay wells. The pupae obtained from the 1996 collections were placed in rearing cages and emerging adults were mass mated. The $\mathrm{F}_{1}$ progeny were used for bioassays of the Cry1 Ab toxin. Rearing procedures for European corn borer were based on those developed at the USDA-ARS Corn Insects Research Unit in Ames, IA (Guthrie et al., 1965). Field collected larvae for both 1996 and 1997 were monitored for both disease and parasitism so that overall survivorship between Event 176 and conventional hybrids could be compared.
Fitness comparisons. In 1997, individual pupal weights were recorded for 25 randomly selected males and females for each collection. Individual pupae were sexed, and placed in separate male and female emergence cages until eclosion. Virgin males and females eclosing on the same day were paired and held in individual mating cages. Ten individual mated pairs were obtained for each collection site. Egg masses from mated females deposited on wax paper positioned at the top of each cage were harvested, counted, and weighed daily. Time to oviposition and longevity of both males and females were also recorded.

Bioassays. Progeny of 1996 field collections were bioassayed by exposing neonate larvae ( $<24 \mathrm{~h}$ after hatching) to artificial diet treated with the Cry1 Ab toxin (Marçon et al., 1999). The rearing diet developed for Heliothis virescens (King et al., 1985) and adapted for European corn borer was used in place of European corn borer diet for Bt bioassays because it is relatively inexpensive, required less time for preparation, and larval growth was comparable to the standard rearing diet through the first several instars (Marçon et al., 1999). Purified Cry1Ab was obtained from the Bacillus thuringiensis kurstaki HD1-9 strain, which produces only the Cryl Ab protein. This material was provided by the Novartis Corp. (Research Triangle Park, NC) in 1995. The crystal protein preparation was obtained by density gradient centrifugation and contained approximately $98 \%$ crystal protein, as determined by phase contrast microscopy. Stock solutions of toxin were stored at $-80^{\circ}$ until use.

Bioassays were performed in 128 well trays (each well $16 \mathrm{~mm}$ diam. $\times 16 \mathrm{~mm}$ height; CD International, Pitman, NJ) as previously described (Marçon et al., 1999). Diet (1 $\mathrm{ml}$ ) was dispensed into each well and allowed to solidify. Seven concentrations of toxin that produce a range of mortality between 0 and $100 \%$ were used, and dilutions were made in $0.1 \%$ Triton-X 100 non-ionic detergent to obtain uniform spreading onto the diet surface. Each well was treated with $30 \mu \mathrm{l}$ of the appropriate solution. Control treatments consisted of wells treated with $0.1 \%$ Triton-X 100 only. Wells were allowed to air dry for $1 \mathrm{~h}$, and one neonate larva was transferred into each well. Wells were then covered with vented lids (CD International), and trays were held at $27{ }^{\circ} \mathrm{C}, 24 \mathrm{~h}$ scotophase, and $80 \%$ r.h. Mortality was recorded seven days later. When recording mortality, larvae that had not grown beyond first instar and were $\leq 0.1 \mathrm{mg}$ in weight were considered to be dead (Marçon et al., 1999). 
Bioassays of the Cry1 Ab toxin were repeated 2-4 times for each population, depending on availability of larvae. Concentrations were replicated three times for each bioassay (total of 48 larvae per concentration per bioassay).

Statistical analyses. Mortality data were analyzed by probit analysis (Finney, 1971) using POLO-PC (LeOra software, 1987). A significant chi-square indicated a poor fit of observed mortality responses. The significance of differences between slopes of the Event 176 collection and the conventional collections was determined by the likelihood ratio test for parallelism and equality (Savin et al., 1977) for each population. If the hypothesis was rejected, pairwise comparisons were performed and significance was declared when confidence intervals did not overlap (Savin et al., 1977).

Pupal weight data were analyzed by a multifactorial analysis of variance in which collection site, hybrid, and sex were analyzed as main effects. Data were pooled across collections sites and percent survival and parasitism were transformed by the arcsine proportion (Steel \& Torrie, 1980) and analyzed by a paired difference $t$-test. Fitness comparisons obtained from single matings were subjected to multiple analysis of variance (PROC GLM, option MANOVA; SAS, 1988) to determine the overall significance of differences between European corn borer larvae collected from Event 176 and conventional hybrids.

\section{Results}

Bioassays. The susceptibility of $\mathrm{F}_{1}$ neonate progeny obtained from parental populations consisting of field-collected, diapausing larvae from paired Event 176 and conventional corn hybrids and exposed to purified Cry1 $\mathrm{A}(\mathrm{b})$ toxin is presented in Table $1 . \mathrm{LC}_{50}$ values ranged from 4.11 $\mathrm{ng} \mathrm{cm}-2$ (Waverly, NE) to $11.95 \mathrm{ng} \mathrm{cm}-2$ (Lincoln, IL) for conventional hybrids and $2.80 \mathrm{ng} \mathrm{cm}-2$ (Newark, DE) to 10.96 (Earlham, IA) for Event 176 hybrids. Although differences in slopes were indicated in a few of the populations tested, there were no significant differences indicated in susceptibility between the conventional and Event 176 collections based on non-overlapping confidence intervals (Table 1).

Pupal weight. Comparisons of $O$. nubilalis pupal weights are presented in Figure 1, and the results from the analysis of variance are presented in Table 2. Pupal weights did not

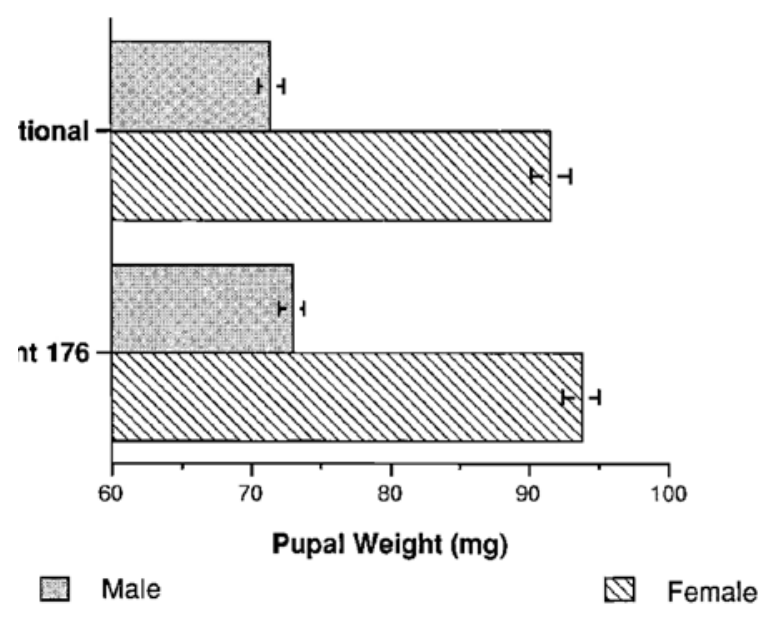

Figure 1. Male and female pupal weights from larvae developing on conventional and Event 176 hybrids. Bars represent standard errors ( $N=146$ for Event 176 males, 142 for conventional females, 152 for Event 176 females, and 148 for conventional females).

differ significantly between those derived from Event 176 and conventional hybrids. Females were approximately $30 \%$ heavier than males, and significant differences existed in pupal weights among collection sites. A significant interaction existed between hybrid and collection site. Because collections did not occur at the same time nor represent the same hybrid at each collection site such interactions were not unexpected.

Survivorship and fitness. Comparison of $O$. nubilalis survivorship and parasitism is presented in Figure 2. Two hymenopteran parasitoids of $O$. nubilalis larvae were collected and identified and mortality due to parasitism recorded. The two parasitoids identified were Macrocentrus grandii Goidanich (Braconidae) and Eriborus terebrans (Gravenhorst) (Ichneumonidae). Significantly higher rates of survival and lower rates of parasitism $(\mathrm{P}<0.05)$ were observed with the larvae collected from Event 176 hybrids relative to larvae obtained from conventional hybrids. Results from fitness comparisons obtained from single pair matings of virgin males and females are presented in Table 3. The multivariate analysis of variance indicated that there were no significant differences $(P>0.05)$ in the overall profile of fitness factors between the insects collected from conventional and Event 176 plants.

\section{Discussion}

As observed in previous assessments of Bt susceptibility (Siegfried et al., 1995; Marçon et al., 1999, Siegfried 
Table 1. Susceptibility of European corn borer neonate larvae from parental populations collected from Event 176 (Bt) and non-Bt hybrids (CC)

\begin{tabular}{|c|c|c|c|c|c|}
\hline Collection Site & Hybrid & Slope \pm SE & $\mathrm{LC}_{50}(95 \% \text { F.L. })^{\mathrm{a}, \mathrm{b}}$ & LC $_{90}(95 \% \text { F.L. })^{\mathrm{a}, \mathrm{b}}$ & $x^{2 c}$ \\
\hline \multirow[t]{2}{*}{ Templeton, IA } & $\mathrm{CC}$ & $2.26 \pm 0.33$ & $5.86(1.80-9.10)$ & $21.67(13.78-79.75)$ & $13.4^{\mathrm{d}}$ \\
\hline & $\mathrm{Bt}$ & $3.36 \pm 0.61$ & $6.27(2.72-8.46)$ & $15.12(11.34-31.59)$ & $13.7^{\mathrm{d}}$ \\
\hline \multirow[t]{2}{*}{ Polk, NE } & $\mathrm{CC}$ & $3.82 \pm 0.44$ & $6.88(5.87-7.83)$ & $14.89(12.82-18.28)$ & 3.8 \\
\hline & $\mathrm{Bt}$ & $2.81 \pm 0.41$ & $5.76(4.85-6.64)$ & $16.78(13.90-21.74)$ & 4.4 \\
\hline \multirow[t]{2}{*}{ La Porte City, IA } & $\mathrm{CC}$ & $2.64 \pm 0.34$ & $8.03(5.14-10.59)$ & $24.53(17.74-47.04)$ & 8.3 \\
\hline & $\mathrm{Bt}$ & $2.32 \pm 0.22$ & $8.07(5.36-11.22)$ & $28.70(18.90-66.02)$ & $13.4^{\mathrm{C}}$ \\
\hline \multirow[t]{2}{*}{ Earlham, IA } & $\mathrm{CC}$ & $1.92 \pm 0.18$ & $8.60(7.23-10.16)$ & $40.14(30.52-58.42)$ & 3.3 \\
\hline & $\mathrm{Bt}$ & $2.65 \pm 0.30^{*}$ & $10.96(7.73-14.39)$ & $33.33(22.97-77.19)$ & 11.2 \\
\hline \multirow[t]{2}{*}{ Etma Green, IN } & $\mathrm{CC}$ & $3.21 \pm 0.37$ & $5.81(4.24-7.26)$ & $14.58(11.38-19.58)$ & 7.2 \\
\hline & $\mathrm{Bt}$ & $2.02 \pm 0.18^{*}$ & $4.89(2.74-7.42)$ & $21.10(13.05-52.60)$ & $15.7^{\mathrm{d}}$ \\
\hline \multirow[t]{2}{*}{ Clinton, IL } & $\mathrm{CC}$ & $2.54 \pm 0.20$ & $6.48(5.13-8.01)$ & $20.71(15.71-30.96)$ & 7.2 \\
\hline & $\mathrm{Bt}$ & $1.71 \pm 0.16^{*}$ & $8.06(5.14-12.43)$ & $45.17(25.01-152.2)$ & $14.3^{\mathrm{d}}$ \\
\hline \multirow[t]{2}{*}{ Clunette, IN } & $\mathrm{CC}$ & $2.57 \pm 0.22$ & $5.24(4.61-5.88)$ & $16.51(13.77-20.73)$ & 2.9 \\
\hline & $\mathrm{Bt}$ & $2.10 \pm 0.18$ & $5.72(4.09-7.54)$ & $23.26(16.26-41.58)$ & 8.8 \\
\hline \multirow[t]{2}{*}{ Newark, DE } & $\mathrm{CC}$ & $2.86 \pm 0.24$ & $5.18(4.46-5.92)$ & $14.51(12.26-17.97)$ & 3.1 \\
\hline & $\mathrm{Bt}$ & $2.66 \pm 0.23$ & $2.80(2.23-3.90)$ & $8.50(6.75-11.69)$ & 5.5 \\
\hline \multirow[t]{2}{*}{ Wyman, IA } & $\mathrm{CC}$ & $3.07 \pm 0.25$ & $5.29(4.66-5.96)$ & $13.83(11.81-16.89)$ & 2.0 \\
\hline & $\mathrm{Bt}$ & $2.53 \pm 0.23$ & $3.05(1.92-4.23)$ & $9.81(6.84-18.53)$ & $13.4^{\mathrm{d}}$ \\
\hline \multirow[t]{2}{*}{ Clunette, IN } & $\mathrm{CC}$ & $2.57 \pm 0.22$ & $5.24(4.61-5.88)$ & $16.51(13.77-20.73)$ & 2.9 \\
\hline & $\mathrm{Bt}$ & $2.10 \pm 0.18$ & $5.72(4.09-7.54)$ & $23.26(16.26-41.58)$ & 8.8 \\
\hline \multirow[t]{2}{*}{ Landisville, NC } & $\mathrm{CC}$ & $2.48 \pm 0.21$ & $4.72(2.70-8.36)$ & $15.50(8.67-64.75)$ & 2.9 \\
\hline & $\mathrm{Bt}$ & $3.12 \pm 0.29$ & $6.87(4.91-8.92)$ & $17.68(13.04-30.52)$ & $12.3^{\mathrm{d}}$ \\
\hline \multirow[t]{2}{*}{ Waverly, NE } & $\mathrm{CC}$ & $3.46 \pm 0.46$ & $4.11(2.96-5.06)$ & $9.65(7.77-13.96)$ & 5.8 \\
\hline & $\mathrm{Bt}$ & $2.80 \pm 0.26$ & $5.83(4.46-6.71)$ & $15.98(12.67-22.50)$ & 5.8 \\
\hline \multirow[t]{2}{*}{ Lincoln, IL } & $\mathrm{CC}$ & $3.14 \pm 0.28$ & $11.95(9.40-15.07)$ & $30.57(22.72-50.76)$ & 10.1 \\
\hline & $\mathrm{Bt}$ & $2.53 \pm 0.26$ & $9.12(6.82-11.65)$ & $29.34(21.28-50.76)$ & 7.5 \\
\hline
\end{tabular}

\footnotetext{
${ }^{a}$ ng Cry $1 \mathrm{Ab} \mathrm{cm}^{-2}$ of diet surface; Each bioassay replicated twice on three different dates $(N=768)$; F.L. $=$ fiducial Limits ${ }^{\mathrm{b}}$ No significant differences detected between Event 176 and conventional collections based on overlapping confidence intervals.

${ }^{\mathrm{c}}$ Degrees of Freedom $=5$.

${ }^{\mathrm{d}}$ Chi-square significant $(\mathrm{P}<0.05)$.

* Slopes significantly different $(\mathrm{P} \leq 0.05)$ determined by likelihood ratio test of equality.
}

Table 2. Analysis of variance table for male and female pupal weights for $O$. nubilalis larvae collected from Event 176 and conventional hybrids ${ }^{\mathrm{a}}$

\begin{tabular}{llrrl}
\hline Source & df & MSE & \multicolumn{1}{l}{ F } & P \\
\hline Collection & 5 & 854.5 & 4.65 & 0.004 \\
Hybrid & 1 & 17.8 & 0.10 & 0.759 \\
Sex & 1 & 59963.9 & 326.19 & 0.0001 \\
Collection $\times$ hybrid & 5 & 1104.4 & 6.01 & 0.0001 \\
Collection $\times$ sex & 5 & 159.1 & 0.87 & 0.504 \\
Hybrid $\times$ sex & 1 & 475.6 & 2.59 & 0.108 \\
Collection $\times$ hybrid $\times$ sex & 5 & 157.1 & 0.85 & 0.515 \\
\hline
\end{tabular}

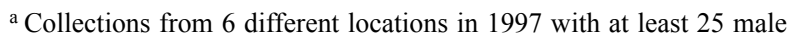
and 25 female pupae weighed from each collection site. et al., 2000), significant variation exists among the populations examined. However, the level of variation regardless of hybrid (3.9-fold at the $\mathrm{LC}_{50}$ ) is similar to the original baseline data collected in 1995 prior to the commercial release of transgenic $\mathrm{Bt}$ corn (3.6-fold at the $\mathrm{LC}_{50}$ ) (Marçon et al., 1999). Although bioassay results from 1996 indicate a trend toward increased Cry $1 \mathrm{Ab}$ tolerance among the populations examined relative to baseline data collected prior to commercial release (Marçon et al., 1999), we believe this trend reflects the stability of the toxin during long-term storage rather than a true change in susceptibility. Results from similar monitoring experiments in 1997 with populations of similar geographic origin and with a new preparation of $\mathrm{Cry} 1 \mathrm{Ab}$, indicate a return to the 
original baseline levels of susceptibility (B. Siegfried, unpubl.). It is therefore unlikely that the differences in response to the Bt toxin among the populations are the result of localized selection for resistance and are more likely the result of natural variability in response to the Bt toxin or sampling artifacts due to the relatively small sample sizes (Robertson et al., 1995). Given the relative insensitivity of the bioassay techniques employed (Roush \& Miller, 1986; ffrench-Constant \& Roush, 1990), slight increases in resistance frequencies might have gone undetected. However, exposure to the Event 176 hybrids among the populations examined did not cause detectable shifts in susceptibility and the majority of individuals completing development on Event 176 are susceptible homozygotes.

European corn borer larval development on Event 176 plants did not have a measurable adverse effect on fitness. If larvae developing on Event 176 were adversely affected by exposure to the Bt toxin, reduced fitness might have been expected. Larvae reared on sublethal concentrations of Bt incorporated into artificial diet experience extended larval development and reduced pupal weights (B. Siegfried, unpubl.). Overall pupation rates were statistically higher among larvae collected from Event 176 hybrids. We were unable to determine the rate of mortality caused by diseases because of secondary infections that may have resulted from mechanical injury during the collection process (L. Lewis, USDA-ARS Corn Insects Research Lab, Ames IA, personal communication). Significantly higher rates of parasitism were recorded among populations collected from conventional corn hybrids, and these differences are likely to have contributed to the overall differences in survival noted previously. The lower rates of parasitism among larvae obtained from Event 176 hybrids may be related to the high level of first generation European corn borer control provided by the Event 176 hybrids (Koziel et al., 1993). Such control would reduce host availability and therefore, suppression of parasitoid populations in subsequent generations is not unexpected. In contrast, conventional hybrids would have provided a more readily available population of first brood European corn borer larvae allowing increased numbers of parasitioids to develop relative to the Event 176 hybrids.

These results in combination indicate that during the first year of commercially available Event 176 corn, there was no detectable change in Cry1 Ab susceptibility among O. nubilalis populations that developed on Event 176 hybrids. Furthermore, those larvae that completed development on Event 176 corn did not appear to be adversely affected. It is uncertain, however, whether these larvae avoided feeding on tissue expressing the Bt toxin or if they were able to compensate for initial sublethal effects during later stages of development. Regardless of potential exposure to the toxin, there is no indication that larvae completing development on Event 176 hybrids have increased tolerance to the Cry1 $\mathrm{Ab}$ toxin or were significantly adversely affected.

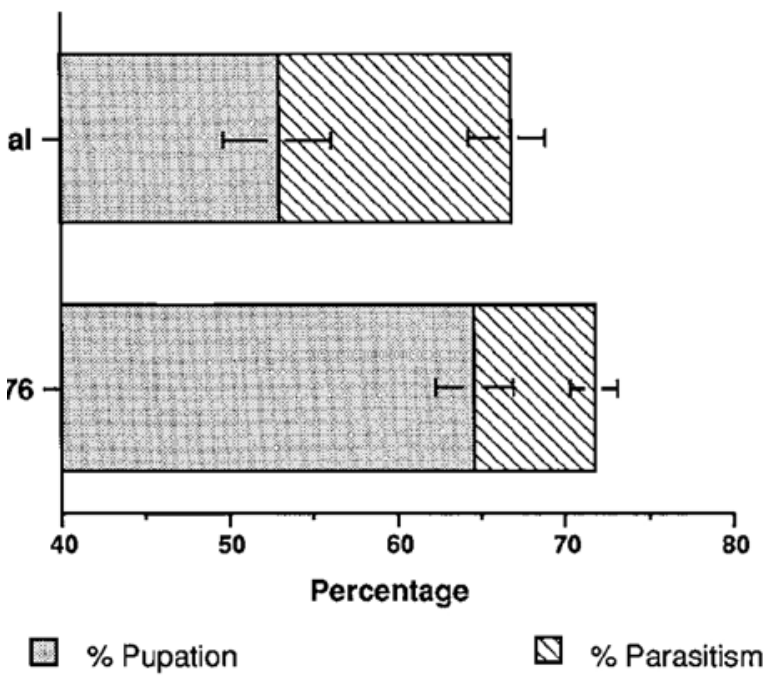

Figure 2. Pupation rates and parasitism of larvae developing on conventional and Event 176.

Table 3. Fitness comparison of European corn borer that have completed larval development on Event 176 and conventional hybrids ${ }^{a}$

\begin{tabular}{lrc}
\hline Fitness Parameter & \multicolumn{1}{c}{ Event $176^{\mathrm{b}}$} & \multicolumn{1}{c}{ Conventional hybrid $^{\mathrm{c}}$} \\
\hline Male longevity (d) & $11.49 \pm 0.59$ & $12.39 \pm 0.63$ \\
Female longevity (d) & $12.11 \pm 0.56$ & $12.55 \pm 0.60$ \\
First oviposition (d) & $4.84 \pm 0.45$ & $4.07 \pm 0.35$ \\
Total egg masses & $4.42 \pm 0.41$ & $4.94 \pm 0.42$ \\
Egg mass weight (mg) & $15.41 \pm 1.51$ & $16.44 \pm 1.71$
\end{tabular}

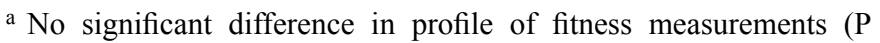
$>0.05$ by multivariate analysis of variance, PROC GLM, option MANOVA, SAS Institute, 1985) differences were detected for any of the comparisons tested.

${ }^{\mathrm{b}}$ Mean $\pm \mathrm{SEM} ; \mathrm{N}=56$ single pair matings from five different collections obtained in 1997.

${ }^{\mathrm{c}}$ Mean $\pm \mathrm{SEM} ; \mathrm{N}=54$ single pair matings from five different collections obtained in 1997. 


\section{Acknowledgements}

The authors acknowledge the contributions of Christine King and Jessica Nearman for colony maintenance and field collections. R. Wright and T. Hunt provided critical review of an earlier draft of this manuscript. Funding for this work was provided by Novartis Seeds Inc. and Mycogen Seeds Inc. This is journal series No. 12859 of the University of Nebraska Agricultural Experiment Station and contribution No. 1051 of the Department of Entomology.

\section{References}

Andow, D. A. \&W. D. Hutchison, 1998. Bt-corn resistance management. In: M. Mellon \& J. Rissler (eds), Now or Never: Serious New Plans to Save a Natural Pest Control. Union of Concerned Scientists, Cambridge, MA, pp. 19-66.

Finney, D. J., 1971. Probit Analysis. Cambridge University Press, England, $333 \mathrm{pp}$.

ffrench-Constant, R. H. \& R. T. Roush, 1990. Resistance detection and documentation: the relative role of pesticidal and biochemical assays. In: R. T. Roush \& B. E. Tabashnik (eds), Pesticide Resistance in Arthropods. Chapman Hall, New York, pp. 4-37.

Gould, F., 1998. Sustainability of transgenic insecticidal cultivars: integrating pest genetics and ecology. Annual Review of Entomology 43: 701-726.

Guthrie, W. D., E. S. Raun, F. F. Dicke, G. R Pesho \& S. W. Carter, 1965. Laboratory production of European corn borer egg masses. Iowa State Journal of Science 40: 665-683.

International Life Sciences Institute, 1998. An evaluation of insect resistance management in Bt field corn: A science-based framework for risk assessment and risk management. ILSI Press, Washington, D.C., 78 pp.

King, E. G., G. G. Hartley, D. F. Martin \&M. L. Laster, 1985. Largescale rearing of a sterile backcross of the tobacco budworm (Lepidoptera: Noctuidae). Journal of Economic Entomology 78: $1166-1172$.

Koziel, M. D., F. L Belang, C. Bowman, N. B. Carozzi, R. S. Kadwell, K. Launis, K. Lewis, D. Maddox, D. Mcpherson, M. R.
Mefhji, E. Merlin, R. Rhodes, G. W. Warren, M. Wright \& S. V. Evola, 1993. Field performance of elite transgenic maize plants expressing an insecticidal protein derived from Bacillus thuringiensis. Biotechnology 11: 194-200.

LeOra Software, 1987. POLO-PC. A User's Guide to Probit and Logit Analysis. Berkeley, CA.

Marçon, P. C. R. G., L. G. Young, K. L. Steffey \& B. D. Siegfried, 1999. Baseline susceptibility of European corn borer (Lepidoptera: Crambidae) to Bacillus thuringiensis toxins. Journal of Economic Entomology 92: 279-285.

Ostlie, K. R., W. D. Hutchison \& R. L. Hellmich, 1997. Bt corn and European corn borer: long-term success through resistance management. North Central Regional Extension Publication, University of Minnesota Extension Service, St. Paul, MN.

Robertson, J. L., H. K. Preisler, S. S. NG, L. A. Hickle \& W. D. Gelernter, 1995. Natural variation: a complicating factor in bioassays with chemical and microbial pesticides. Journal of Economic Entomology 88: 1-10.

Roush, R. T. \& G. L. Miller, 1986. Considerations for design of insecticide resistance monitoring programs. Journal of Economic Entomology 79: 293-298.

SAS Institute Inc., 1988. SAS Procedures Guide, Release 6.03 Edition. SAS Institute Inc., Cary-NC, 441 pp.

Savin, N. E., J. L. Robertson \& R. M. Russell, 1977. A critical evaluation of bioassay in insecticide research: likelihood ratio tests of dose-mortality regression. Bulletin of Entomological Society of America 23: 257-266.

Siegfried, B. D., P. C. R. G. Marçon, J. F. Witkowski, R. J. Wright \& G. W. Warren, 1995. Susceptibility of field populations of the European corn borer, Ostrinia nubilalis (Hübner) (Lepidoptera: Pyralidae), to the microbial insecticide Bacillus thuringiensis Berliner. Journal of Agricultural Entomology 12: 257-263.

Siegfried, B. D., T. Spencer \& J. L. Nearman, 2000. Baseline susceptibility of the corn earworm (Lepidoptera: Noctuidae) to the CryIAb toxin from Bacillus thuringiensis. Journal of Economic Entomology 93: 1265-1268.

Steele, R. G. D. \& J. H. Torrie, 1980. Principles and Procedures of Statistics: a Biometrical Approach, 2nd ed. McGraw-Hill, New York. 